\title{
Estruturas Domésticas e Grupos de Interesse: A Formação da Posição Brasileira para Seattle*
}

Maria Izabel V. de Carvalho**

\section{Introdução}

A partir da Rodada Uruguai e da criação da Organização Mundial do Comércio (OMC), as negociações multilaterais de comércio têm produzido resultados que afetam um conjunto cada vez maior de interesses no interior dos Estados-membros. As mudanças que vêm se desenvolvendo desde então abrangeram o escopo dos temas tratados e o processo de tomada de decisão no âmbito da OMC.

Paralelamente à tradicional negociação sobre a derrubada de barreiras ao comércio, desenvolveu-se, a partir da Rodada Uruguai, uma

\footnotetext{
*Esta é uma versão bastante modificada do trabalho "O Processo de Formulação da Agenda: Brasil e Estados Unidos na Rodada do Milênio da OMC", apresentado no GT 13 Política Internacional, no XXIV Encontro Anual da Associação Nacional de Pós-Graduação e Pesquisa em Ciências Sociais - Anpocs, Caxambu, MG, 2000. Agradeço os comentários então recebidos por parte de Leticia Pinheiro e Flavia de Campos Mello. Aceito para publicação em dezembro de 2003.

**Professora do Instituto de Relações Internacionais da Universidade de Brasília e pesquisadora visitante do Centre for International Studies da London School of Economics and Political Science.
}

CONTEXTO INTERNACIONAL Rio de Janeiro, vol. 25, nº 2, julho/dezembro 2003, pp. 363-401. 
agenda mais ampla para os acordos multilaterais, incluindo regras e disciplinas para temas não diretamente vinculados ao comércio, tais como direitos de propriedade intelectual e investimentos internacionais.

Além disso, a Rodada Uruguai consagrou as medidas de graduação, ou seja, o estabelecimento de prazos para os países em desenvolvimento se adaptarem,inclusive por meio de mudanças nas legislações internas, às regras negociadas. Eliminou também do Acordo do GATT a "cláusula do avô", pela qual se permitia a não implementação de um acordo referente à Parte II (regras sobre comércio) caso ele fosse inconsistente com a legislação interna (Thorstensen, 1999:36).

A instituição da OMC implicou, por sua vez, a criação e a consolidação de confidence building measures (Lafer,1999:25-53). Tais medidas, que se constituem no princípio da transparência, no sistema de solução de controvérsias, no consenso e no "empreendimento único" como elementos essenciais do processo de tomada de decisão (ibidem), contribuem para posicionar os membros da OMC, na expectativa de que os interesses de todos serão, em alguma medida, atendidos. Desenvolver-se, dessa maneira, a confiança mútua necessária para garantir a efetiva operação daquele organismo internacional, já que ele é passível de sofrer problemas advindos de comportamentos "caronas" e de deserção voluntária e involuntária ${ }^{1}$.

Porém, os mecanismos de "construção de confiança" tornaram o processo decisório, no âmbito da $\mathrm{OMC}$, mais rígido e, por conseguinte, mais coativo do desempenho de seus membros e das decisões efetuadas por eles em seus contextos domésticos.

Além disso, como destacam Goldstein e Martin (2000), com a criação da OMC, em 1995, o processo de regulamentação multilateral do comércio internacional tem adquirido características de maior precisão e transparência. Em conseqüência, isto possibilita o desenvolvimento, na esfera doméstica, de percepção mais acurada nos diversos 
Estruturas Domésticas e Grupos de Interesse:

A Formação da Posição Brasileira...

grupos econômicos e sociais acerca da incidência dos custos e dos benefícios das regras acordadas, gerando-se, assim, um aumento significativo da mobilização desses grupos com vistas a influenciar os governos e a OMC.

Os efeitos das transformações que se desenvolveram na esfera da regulação do comércio internacional, devido à abrangência da agenda, aos mecanismos de "construção de confiança", à precisão e à transparência das regras, só poderão ser adequadamente avaliados para o processo decisório da política externa brasileira se forem considerados os fatores que tornaram a sociedade mais permeável à influência daquelas mudanças, assim como as instituições e as estruturas políticas domésticas que filtraram as preferências dos grupos de interesse domésticos.

Em relação ao primeiro aspecto do problema, de acordo com Lima (2000) e Santana (2000; 2001), este artigo ressalta a internacionalização da economia brasileira a partir do início dos anos 90 . A respeito da segunda dimensão, argumenta-se que, dependendo do modo como as estruturas domésticas são constituídas, elas podem contribuir para que um maior ou menor número de interesses possa chegar à arena decisória e influenciar a formulação da política externa.

Além do aumento dos constrangimentos externos decorrentes dos resultados da Rodada Uruguai e da instituição da OMC, na década de 90 também se constataram mudanças no modelo de desenvolvimento econômico do Brasil que tornaram a sociedade brasileira mais sensível aos condicionamentos do mercado internacional.

O modelo desenvolvimentista, fundado em forte atuação do Estado como incentivador, regulador da atividade produtiva e gerador de bens, com base na economia fechada, direcionada a atender à demanda do mercado interno, em vigor no país desde os anos 50, não impulsionava a sociedade a participar das negociações multilaterais de comércio. A transformação desse modelo no final dos anos 80 e sua 
consolidação em meados da década de 90 produziram uma sociedade mais integrada ao meio internacional e, conseqüentemente, mais permeável aos seus efeitos.

Entre as várias modificações ocorridas naquele período - que incluíram a privatização de empresas estatais e a participação do capital estrangeiro em novos setores produtivos, tais como energia e telecomunicações - sobressaiu a liberalização comercial. Como enfatizaram Lima e Santos (1998:27), em um contexto de economia aberta, os resultados das negociações multilaterais de comércio adquirem um caráter distributivo, produzindo "expectativas de perdas e ganhos diferenciados, advindos de eventuais compromissos internacionais". Em decorrência, os setores econômicos e sociais afetados por aquelas negociações tendem a mobilizar-se para a defesa de seus interesses.

Entretanto, não é direto o processo pelo qual as preferências dos grupos de interesse se transplantam para a arena internacional. Muitos estudos têm enfatizado a relevância de se considerarem instituições e estruturas políticas domésticas como elementos que intermedeiam o resultado da tomada de decisão e as pressões dos grupos de interesse (cf. Katzenstein, 1976; Weir e Skocpol, 1985; Ikenberry, 1988; Rissen-Kapen, 1995; Keohane e Milner, 1996; Milner, 1997). Entre as várias colaborações feitas a esse respeito, destaca-se o conceito de estruturas domésticas, desenvolvido por Thomas Rissen-Kapen $(1995)^{2}$.

Segundo Rissen-Kapen (1995:21-22), o conceito de estruturas domésticas abrange três dimensões: as instituições políticas do Estado e o seu relacionamento; as estruturas de formação de demanda da sociedade e o grau em que elas são mais ou menos centralizadas; e as redes políticas envolvendo o Estado e a sociedade. As relações entre o Executivo e o Legislativo, os conflitos entre as agências da burocracia governamental, bem como o grau em que o poder decisório é mais ou menos concentrado nas mãos do Executivo são questões focaliza- 
Estruturas Domésticas e Grupos de Interesse:

A Formação da Posição Brasileira...

das na primeira dimensão. A segunda dimensão, por sua vez, compreende a estrutura de formação de demanda da sociedade civil e o grau em que ela é mais ou menos centralizada. Os sistemas de representação de interesses e as normas regulando o processo de formação de coalizões integram a terceira dimensão.

Analisa-se, neste artigo, o modo como ocorreu a preparação do posicionamento brasileiro para a III Conferência Ministerial da OMC em Seattle, EUA, entre 30 de novembro e 3 de dezembro de 1999, focalizando o processo de articulação de interesses do setor privado (empresários e trabalhadores), o relacionamento da sociedade civil com a burocracia governamental e os papéis desempenhados pelo Executivo e pelo Legislativo.

A primeira parte do trabalho examina o processo de organização, mobilização e interferência do setor empresarial na formulação da posição brasileira para Seattle. Por um lado, a influência da internacionalização da economia é destacada como um fator explicativo e significativo do comportamento do empresariado; por outro, investiga-se a constituição de canais de comunicação, ainda que informais, entre setores da burocracia estatal e os grupos de interesse empresariais, repetindo um padrão de articulação de interesses entre esses dois setores que tem caracterizado, independentemente de regime político, o sistema de intermediação de interesses do país desde os anos 30 (Diniz e Boschi, 2000).

A constituição das demandas do movimento sindical e o papel da liberalização econômica nesse processo são averiguados na segunda parte. Observa-se que as centrais sindicais adotaram uma estratégia de "socialização do conflito" (Schattschneider, 1960:3-7) estendendo sua abrangência e buscando, por meio de alianças transnacionais, interferir no desenrolar da negociação da agenda diretamente na OMC e em Seattle. 
A terceira seção pesquisa o grau em que o desenvolvimento de formação da posição brasileira esteve concentrado no Executivo e os vínculos que se estabeleceram entre Estado e sociedade para a formação da posição brasileira. Além disso, deu-se ênfase especial às conexões que, nesse processo, ocorreram entre o setor privado e a diplomacia.

A conclusão discute os resultados à luz do conceito de estruturas domésticas e salienta suas implicações para a credibilidade e o poder de barganha da posição oficial brasileira, de acordo com as sugestões desenvolvidas por estudos recentes de Lima e Santos (1998), Lima (2000) e Santana (2000; 2001), a partir de estudo de Robert Putnam (1993).

\section{Preferências e Organização: O Setor Empresarial}

Até o início da década de 90, o empresariado brasileiro participava de modo limitado e pouco organizado das negociações no âmbito do GATT. Apenas alguns setores específicos que produziam para o mercado externo procuraram se envolver naquelas negociações (Rios, 1999). O longo período de implementação de um modelo de substituição de importações e de economia fechada, somado à pouca influência do contexto das negociações multilaterais de comércio internacional para os países em desenvolvimento até meados dos anos 80, foram fatores que não incentivaram o envolvimento do setor produtivo no processo de negociação junto ao GATT (Lima e Santos, 1998).

Todavia, o uso crescente de barreiras não-tarifárias contra os produtos brasileiros e o aumento das queixas contra a aplicação de mecanismos semelhantes pelo país, que se ampliaram no final dos anos 80 , alertaram "os empresários para todo o arcabouço jurídico já existente no GATT e em revisão na Rodada Uruguai” (Rios,1999:6). A per- 
Estruturas Domésticas e Grupos de Interesse:

A Formação da Posição Brasileira...

cepção dos constrangimentos do ambiente externo sobre os interesses empresariais teve como resultado a mobilização da Confederação Nacional da Indústria (CNI), da Confederação Nacional da Agricultura (CNA), da Associação de Exportadores Brasileiros (AEB) e de alguns grupos empresariais para acompanhar as negociações que se processavam em Genebra a partir de $1993^{3}$. Entretanto, o processo de mudança da economia brasileira ainda se encontrava no início e, portanto, não estavam claros para o setor empresarial os custos de se manter afastado das negociações no âmbito da OMC. Em consequiência, a primeira mobilização das organizações representativas dos interesses empresariais foi incipiente: "[...] não houve coordenação de esforços, não houve construção de estratégias e a postura foi essencialmente defensiva" (ibidem).

A criação da OMC, a amplitude e a diversificação da agenda de negociação a partir da Rodada Uruguai, somadas à intensificação da abertura comercial do início da década de 90 e à percepção do empresariado de que a ausência nas negociações para criação e implementação do Mercosul, bem como a não-participação na Rodada Uruguai, resultando em perdas significativas para o setor, conduziram os empresários a se organizarem de forma efetiva para influenciarem as negociações multilaterais de comércio das quais o Brasil participava.

Em consequiência, em 1996, sob a liderança da CNI, foi criada a organização supra-setorial do empresariado Coalizão Empresarial Brasileira (CEB) para efeito de

“[...] coordenar o processo de influência do setor empresarial brasileiro nos processos de negociações internacionais [...], buscando a formação do consenso interno, o estabelecimento de canais de diálogo com o governo brasileiro e a atuação coordenada em foros empresariais internacionais" ${ }^{, 4}$.

A adesão à CEB era voluntária e a ela somaram-se organizações representativas dos diversos setores produtivos (agricultura, indústria e serviços) bem como empresas isoladas. Inicialmente, a preocupação 
da CEB centrou-se nas negociações da Área de Livre Comércio das Américas (ALCA) já em curso, em relação às quais “[...] não havia informação no âmbito empresarial sobre o que se passava na negociação, não havia ainda nenhum processo de reflexão, nem de influência do setor empresarial nas negociações" . Porém, posteriormente, a CEB atuou na elaboração da postura brasileira para as negociações no âmbito da OMC.

A instituição da CEB representou um momento de inflexão importante no processo de arregimentação e estruturação das atividades participativas dos empresários em torno das negociações multilaterais de comércio. Além de se tornar a entidade responsável por levar as demandas do setor produtivo ao governo, a CEB também passou a disponibilizar informações sobre as negociações e a contribuir para avaliar o seu impacto sobre os interesses empresariais. Em conseqüência, com sua criação a influência do setor produtivo nesse âmbito passou a ocorrer de forma mais integrada e efetiva.

O resultado disso já pôde ser observado na III Reunião Ministerial da ALCA, em 1997, em Belo Horizonte. Para tal Reunião, a CEB articulou uma proposta comum entre os diferentes setores econômicos (agricultura, indústria e serviços) e apoiou a posição gradualista, defendida pelo Brasil, para as negociações com vistas à criação da ALCA. A atuação da CEB cooperou para aumentar a credibilidade da posição brasileira e foi um dos fatores que colaboraram para o seu sucesso (Santana, 2001).

Se, por um lado, a CEB respondeu aos impactos das transformações do ambiente externo e interno, por outro, as mudanças que se processaram na economia brasileira acabaram por ter um impacto diferenciado entre os vários setores produtivos, gerando divergências a respeito da postura que o país deveria encaminhar externamente. Enquanto a indústria se ressentiu do processo de liberalização econômica, a agricultura acabou se beneficiando do mesmo. 
Estruturas Domésticas e Grupos de Interesse: A Formação da Posição Brasileira...

A exposição à concorrência internacional, somada à redução do crédito oficial conduziram à diminuição dos custos médios por parte dos agricultores, que resultou "em intenso e sistemático aumento da produtividade" responsável pelo crescimento da produção durante a década de 90 (Baumann, 1999:37). A abertura comercial, reduzindo as tarifas dos insumos para a agricultura, assim como o desenvolvimento tecnológico propiciado pela Embrapa, com a criação de espécies adaptadas às regiões de fronteira agrícola como o cerrado, muito contribuíram para o aumento da produtividade do setor (Dias e Amaral, 1999:236-241). A taxa de crescimento da indústria para o período 1990-1996, por sua vez, foi de $9 \%$ no caso dos produtores de bens duráveis de consumo, enquanto no setor de bens de capital mostrou-se praticamente nula, e no setor manufatureiro alcançou menos de 2\% (Baumann, 1999:32).

As diferenças econômicas entre os dois setores resultaram em uma postura mais liberalizante da agricultura vis-à-vis a indústria nas negociações multilaterais de comércio. Dessa maneira, a agricultura passou a demandar a liberalização de insumos industriais e de bens de capital utilizados na sua cadeia produtiva, atingindo, por conseguinte, as preferências de determinados setores industriais que não estavam preparados para uma abertura tão rápida ${ }^{6}$.

A posição mais liberalizante da agricultura-que já tinha se expressado durante o processo de articulação das preferências empresariais conduzido pela CEB, com vistas a influenciar na conformação da ALCA na Reunião de Belo Horizonte, em 1997 (Santana, 2000) - levou à instituição de um organismo específico para compor as demandas do agronegócio, setor que, voltado para a exportação, foi favorecido de modo mais intenso pelas mudanças ocorridas na agricultura desde o início dos anos 90, referidas anteriormente ${ }^{7}$. Dessa maneira, em fevereiro de 1999, a CNA, a Associação Brasileira de Agribusiness (Abag) e a Organização das Cooperativas Brasileiras (OCB) criaram o Fórum Permanente de Negociações Agrícolas Internacionais 
(Fórum), com o objetivo de "[...] obter resultados positivos na OMC através da integração dos esforços [...] a nível do setor privado, e do estabelecimento de um diálogo aberto com o Governo",

Vários foram os fatores que contribuíram para a criação do Fórum. Em primeiro lugar, a constatação de que a inexistência de um organismo que coordenasse os diferentes setores agrícolas produzira “[...] perdas inestimáveis de diversos setores do agronegócio na Rodada Uruguai do GATT e até mesmo no Mercosul"9.

Em segundo lugar, a consideração de que o espaço da Coalizão Empresarial, apesar de significativo, era insuficiente. Existiam diferenças de preferências dentro da Coalizão - uma postura mais ofensiva da agricultura vis-à-vis uma postura mais defensiva de determinados setores da indústria (indústria de bens de capital, indústria química, eletroeletrônica) - que dificultavam a expressão, junto ao governo, da posição da agricultura ${ }^{10}$.

E, por último, mas não menos importante, havia também conflitos de orientações dentro do Executivo a respeito da posição que o Brasil devia adotar no âmbito das negociações comerciais internacionais. Por conseguinte, a criação do Fórum pretendeu reforçar a posição do agronegócio junto aos seus aliados - o Ministério da Agricultura, Pecuária e Abastecimento (MAPA) - de forma a ampliar o espaço de defesa das preferências deste setor no âmbito do Executivo, ao mesmo tempo que respaldava as preferências do Ministério na instância da burocracia governamental. É importante destacar que a criação do Fórum não conduziu ao abandono da CEB pelas organizações representativas e empresas do setor agrícola. O ambiente da CEB ainda é reconhecido como relevante para a participação das organizações representativas da agricultura e dos seus diferentes setores ${ }^{11}$. O que se verificou, por conseguinte, foi uma estratégia pragmática por parte da agricultura, buscando atuar em diferentes espaços de poder de modo a maximizar os seus interesses. 
Estruturas Domésticas e Grupos de Interesse: A Formação da Posição Brasileira...

Desse modo, como pode ser observado no Quadro 1, não houve divergências significativas entre as propostas de agenda apresentadas pela CEB e pelo Fórum para a Reunião de Seattle (CNI, 1999; Fórum, 1999).

O setor empresarial propôs uma agenda ampla de negociação na qual houve uma postura demandante em relação à agricultura, medidas antidumping, subsídios e medidas compensatórias e atitudes defensivas em relação a bens industriais e serviços. Em relação aos chama-

\section{Quadro 1}

Propostas da Coalizão Empresarial Brasileira e do Fórum Permanente de Negociações Agrícolas Internacionais para a Agenda Brasileira em

Seattle*

\begin{tabular}{|c|c|c|}
\hline & CEB & Fórum \\
\hline Acesso a Mercado (1) & $\begin{array}{l}\text { Não negociação de redução } \\
\text { de tarifas industriais; } \\
\text { redução dos picos, da esca- } \\
\text { lada tarifária e das quotas } \\
\text { em relação aos produtos do } \\
\text { agronegócio. }\end{array}$ & $\begin{array}{l}\text { Redução dos picos, da esca- } \\
\text { lada tarifária e das quotas. }\end{array}$ \\
\hline (2) & $\begin{array}{l}\text { Eliminação das Salvaguar- } \\
\text { das Especiais para os produ- } \\
\text { tos do Acordo Agrícola. }\end{array}$ & $\begin{array}{l}\text { Eliminação das Salvaguar- } \\
\text { das Especiais para os produ- } \\
\text { tos do Acordo Agrícola. }\end{array}$ \\
\hline (3) & $\begin{array}{l}\text { Preocupação com Regras de } \\
\text { Origem, Valoração Adua- } \\
\text { neira, Licenciamento de } \\
\text { Importações e Barreiras } \\
\text { Técnicas. }\end{array}$ & \\
\hline Acordo Antidumping & $\begin{array}{l}\text { Reforço das disciplinas e re- } \\
\text { gras mais claras e unifor- } \\
\text { mes. }\end{array}$ & \\
\hline $\begin{array}{l}\text { Subsídios e Medidas Com- } \\
\text { pensatórias }\end{array}$ & $\begin{array}{l}\text { Reforço das disciplinas e re- } \\
\text { gras mais claras e transpa- } \\
\text { rentes; } \\
\text { incorporação dos subsídios } \\
\text { à exportação de produtos } \\
\text { agrícolas às regras e disci- } \\
\text { plinas da OMC. }\end{array}$ & $\begin{array}{l}\text { Incorporação dos subsídios } \\
\text { à exportação às regras e dis- } \\
\text { ciplinas da OMC. }\end{array}$ \\
\hline
\end{tabular}


Maria Izabel v. de Carvalho

\begin{tabular}{|c|c|c|}
\hline Investimentos & $\begin{array}{l}\text { Maior prazo para o Brasil } \\
\text { apoiar um acordo abrangen- } \\
\text { te nesta área. }\end{array}$ & \\
\hline Serviços & $\begin{array}{l}\text { Interesse na continuidade da } \\
\text { negociação do acordo Servi- } \\
\text { ços; mais prazo para o país } \\
\text { se adaptar à abertura; defen- } \\
\text { de restrição a dumping, sub- } \\
\text { sídios e salvaguardas emer- } \\
\text { genciais. }\end{array}$ & \\
\hline Propriedade Intelectual & $\begin{array}{l}\text { Contrária a níveis mais altos } \\
\text { de patenteamento. }\end{array}$ & \\
\hline Compras Governamentais & $\begin{array}{l}\text { Sem obstáculos a um acordo } \\
\text { nesta área. }\end{array}$ & \\
\hline Comércio e Meio Ambiente & $\begin{array}{l}\text { Sem consenso sobre esta } \\
\text { área. }\end{array}$ & $\begin{array}{l}\text { Também não há consenso; a } \\
\text { questão deveria ser tratada } \\
\text { na OMC para evitar o seu } \\
\text { uso protecionista. }\end{array}$ \\
\hline Cláusula Social & $\begin{array}{l}\text { Questão a ser examinada na } \\
\text { OIT. }\end{array}$ & $\begin{array}{l}\text { Questão a ser examinada na } \\
\text { OIT. }\end{array}$ \\
\hline Cláusula da Paz & & $\begin{array}{l}\text { Extinção em final de } 2003 \text {, } \\
\text { segundo o Acordo Agrícola. }\end{array}$ \\
\hline $\begin{array}{l}\text { Multifuncionalidade na } \\
\text { Agricultura }\end{array}$ & & $\begin{array}{l}\text { Evitar, a todo custo, o seu } \\
\text { uso protecionista; manter a } \\
\text { questão na "caixa verde". }\end{array}$ \\
\hline
\end{tabular}

* Baseado em CNI (1999) e Fórum (1999).

dos "novos temas" (investimentos, concorrência, propriedade intelectual e compras governamentais) a posição era de cautela. De acordo com a $\mathrm{CEB}, \mathrm{o}$ Brasil poderia negociar tais temas à medida que fossem contemplados os interesses demandantes ${ }^{12}$.

As propostas da CEB incluíram, ainda, tratamento especial e diferenciado para os países em desenvolvimento nos seguintes temas: tarifas, acordo antidumping e investimentos.

Em relação ao vínculo entre meio ambiente e comércio, a CEB não logrou um consenso. Uma divisão significativa ocorreu entre os setores que já produziam com medidas de proteção ambiental bastante 
elevadas e que tinham interesse em que a questão fosse disciplinada na $\mathrm{OMC}$ e aqueles que temiam a introdução de barreiras tarifárias, caso a questão passasse a ser regulada junto com o comércio ${ }^{13}$.

Quanto à adoção de padrões trabalhistas na OMC (cláusula social) na agenda, houve, inicialmente, algumas dúvidas por parte de setores industriais que sofriam com a concorrência da produção do Sudeste Asiático e da China quanto a essa possibilidade. Posteriormente, chegou-se ao consenso de que a avaliação de padrões trabalhistas deveria ser discutida no âmbito da Organização Internacional do Trabalho $(\mathrm{OIT})^{14}$.

A CEB e o Fórum consideraram, ainda, que a interlocução com o governo era um elemento essencial na formulação da posição negociadora brasileira ${ }^{15}$. Em conseqüência, vínculos, ainda que informais, foram estabelecidos com diversos Ministérios. A CEB e o Fórum interagiram com o Ministério das Relações Exteriores (MRE); a CEB e a CNI atuaram junto ao Ministério de Desenvolvimento, Indústria e Comércio (MDIC); e as organizações que compunham o Fórum junto ao MAPA.

Além disso, o Fórum, o MAPA e o MRE realizaram seis reuniões entre 22 e 29 de julho, em Brasília, Porto Alegre e Curitiba, com diferentes setores do agronegócio (complexo soja, café e açúcar, frutas, lácteos e carne bovina, frangos e suínos, peles e couros, fumos e cigarros), objetivando conhecer os interesses específicos de cada um dos setores para que se fizesse a radiografia dos impactos de possíveis concessões setoriais que subsidiassem as estratégias negociadoras brasileiras (Fórum, 1999:14-15; Gazeta Mercantil, 7/7/1999). Como destacou o subsecretário de Assuntos de Integração Econômica e de Comércio Exterior do Itamaraty, José Alfredo Graça Lima, as rodadas de estudos foram uma inovação, na medida em que permitiam "uma participação mais efetiva do setor privado na elaboração da estratégia brasileira" 16 . 
O desenvolvimento de organizações supra-setoriais representativas dos interesses empresariais, por um lado, e a interação maior com o governo, por outro, colaboraram para que o empresariado participasse mais ativamente na preparação da agenda brasileira para Seattle, contrastando com o baixo envolvimento ocorrido durante as negociações da Rodada Uruguai.

Contudo, os empresários consideraram insuficiente o modo como a relação com o governo se constituiu. Segundo a CEB, o relacionamento com o governo caracterizou-se por sua contingência e não-institucionalização. Além disso, ele não proporcionava informações constantes e transparentes, ou canais de acesso estáveis (CNI, 1999:3).

A não-institucionalização gerava instabilidade e incerteza no relacionamento dos empresários com o governo. $\mathrm{O}$ acesso ao governo ficava dependente "[...] das pessoas que estão ocupando os cargos a cada momento, porque a cada mudança, é preciso reconstruir a confiança [...]. Até construir a confiança é complicado"17.

Da perspectiva da CEB, fazia-se, ainda, necessária a instituição de um sistema de comunicação entre o setor produtivo e o governo que possibilitasse aos empresários o acesso, em tempo hábil, às informações sobre a agenda negociadora, às posições oficiais brasileiras e à evolução das negociações (ibidem).

Além das críticas ao processo de preparação da agenda brasileira, o setor empresarial ressentiu-se, também, de uma participação mais incisiva durante o processo negociador. O sistema de "sala ao lado"em que a informação do que se passa durante as negociações é transmitida por um funcionário do Itamaraty aos interessados - foi considerado incompleto e pouco fidedigno. Os empresários pleitearam a possibilidade de participar mais diretamente das negociações. 
Estruturas Domésticas e Grupos de Interesse: A Formação da Posição Brasileira...

A internacionalização da economia brasileira, efetivamente, foi um fator que possibilitou que os constrangimentos do ambiente externo - sistema de regulação do comércio via OMC - passassem a gerar efeitos distributivos domésticos. Dessa maneira, os empresários perceberam a necessidade de se organizarem para influenciar as negociações multilaterais de comércio na OMC. Com a constituição de organizações supra-setoriais, o setor empresarial passou a ter um envolvimento maior com as negociações no âmbito da OMC. Essas organizações proporcionaram informações, mobilizaram os empresários, avaliaram os impactos possíveis de eventuais concessões e buscaram, por meio de vínculos com o Executivo, influenciar a formação da posição oficial brasileira para a Reunião de Seattle.

Os vínculos que as organizações firmaram com determinados Ministérios, ainda que informais, sugerem terem eles expressado um processo em que, por um lado, a representação dos interesses empresariais se desenvolveu via burocracia governamental, e, por outro, as preferências de partes da burocracia foram reforçadas pelo apoio recebido do setor empresarial ${ }^{18}$.

\section{Preferências e Organização: A Agenda dos Trabalhadores}

Enquanto os grupos de interesse do setor empresarial formaram organizações supra-setoriais para lidar com os desafios colocados pelas negociações multilaterais de comércio em um ambiente doméstico mais permeável às injunções econômicas externas, os grupos de interesse dos trabalhadores reagiram àqueles desafios a partir da estrutura já existente de representação de suas demandas. Além disso, ao lado da internacionalização da economia, os vínculos com organizações internacionais e as alianças transnacionais das centrais sindicais foram fatores significativos para explicar o comportamento e as posições defendidas por esses grupos. Os vínculos internacionais fo- 
ram responsáveis não somente para que os grupos de interesse dos trabalhadores se mobilizassem antes do setor empresarial, como também para que esta mobilização ocorresse em torno de determinadas questões. Por último, os relacionamentos transnacionais das centrais sindicais contribuíram para que a sua atuação se desenvolvesse, desde o início, diretamente junto à OMC.

O impacto negativo do processo de internacionalização da economia sobre o nível de emprego e de renda dos trabalhadores ${ }^{19}$ foi um dos fatores que motivaram as centrais sindicais - a Confederação Única dos Trabalhadores (CUT), a Confederação Geral dos Trabalhadores (CGT) e a Força Sindical (FS) - a se envolverem nas negociações multilaterais de comércio no âmbito da OMC.

Em consequiência, a percepção de que o processo de liberalização econômica não tinha trazido resultados positivos para os trabalhadores condicionou a postura defensiva das centrais sindicais em relação à Conferência de Seattle. Por outro lado, suas relações com a Confederação Internacional de Organizações Sindicais Livres (CIOSL) e com a Organização Regional Interamericana de Trabalhadores (ORIT) filiada à CIOSL ${ }^{20}$ induziram-nas a apoiar a campanha desenvolvida por estas entidades a respeito da introdução da cláusula social e ambiental na OMC. Dessa maneira, a postura do movimento sindical distanciou-o das posições do setor empresarial e do governo brasileiro, conforme será abordado na seção seguinte.

A mobilização do movimento sindical diferenciou-se, ainda, da atuação empresarial na medida em que parte expressiva de suas atividades foi direcionada para agir junto aos organismos internacionais dos quais participava e para estabelecer alianças com centrais sindicais de outros países e com Organizações Não-Governamentais (ONGs), visando influir diretamente no âmbito negociador em Seattle.

O processo de aquisição de informações das centrais sindicais sobre a OMC também se beneficiou de seus relacionamentos internacio- 
nais e transnacionais. Assim, todo procedimento objetivando pressionar as decisões no âmbito da OMC desenvolveu-se de forma mais ativa, antes mesmo do setor empresarial.

A mobilização antecipada do movimento sindical em relação ao setor empresarial concentrou-se em uma questão altamente internacionalizada - a cláusula social. Esta questão, que mobilizara desde 1979 a CIOSL, se transformou, com o passar do tempo, em um foco de atenção e pressão significativo das organizações internacionais do movimento sindical e das ONGs sobre os governos e o GATT.

Dessa maneira, já em 1994, durante a Conferência do GATT em Marraqueche, a CUT apoiou a proposta da CIOSL e também dos Estados Unidos e da França para a adoção, pela OMC, de normas reconhecidas pela OIT, estabelecendo limites mínimos para padrões trabalhistas nas trocas comerciais ${ }^{21}$.

Além disso, a CUT, ainda em 1994, aprovou, no âmbito da Reunião da Executiva Nacional, uma resolução a favor da adoção da cláusula social na OMC. No mesmo ano, em Reunião da OIT, a CGT, representando as centrais sindicais brasileiras, defendeu a inclusão da cláusula social nesse organismo. Tal comportamento do movimento sindical ocorreu mesmo com a oposição do Itamaraty que, por meio de contatos diretos com a CUT, procurou dissuadi-la de sustentar aquela proposta $^{22}$.

Por fim, como resultado das discussões a respeito da relação entre comércio e padrões trabalhistas, surgiu na CUT a idéia de se criar uma organização para verificar em que medida as empresas multinacionais acatavam as normas trabalhistas da $\mathrm{OIT}^{23}$. A organização foi estabelecida em 1997, com a colaboração de várias ONGs e instituições de pesquisa social, passando a se chamar Observatório Social ${ }^{24}$.

A campanha da CIOSL pela adoção da cláusula social com o apoio das centrais sindicais brasileiras desembocou em uma intensa pres- 
são sobre os governos na I Conferência Ministerial da OMC em Cingapura, em 1996. A CUT participou da reunião como representante das organizações trabalhistas brasileiras. A proposta foi formalmente rejeitada naquela Conferência, tendo sido, então, aprovada uma resolução que afirmava ser a OIT o foro adequado para tratar de padrões trabalhistas.

A partir da Conferência de Cingapura, intensificou-se o processo de ampliar as alianças do movimento sindical junto às ONGs. Em face disso, atividades conjuntas entre os dois setores da sociedade civil foram desenvolvidas durante a Reunião da ALCA em Belo Horizonte, em 1997. Da época, datam os vínculos com a Federação de Órgãos para Assistência Social e Educacional (FASE) e com o Instituto Brasileiro de Análises Sociais e Econômicas (IBASE) ${ }^{25}$. A partir das discussões envolvendo a ALCA e a OMC, foi instituída, com o apoio da CUT, a Rede Brasileira de Integração dos Povos (Rebrip), uma articulação de ONGs, movimentos sociais, entidades sindicais e associações profissionais autônomas preocupada com temas de integração regional e de comércio e sediada na Escola Sul da CUT, em Florianópolis ${ }^{26}$.

Posteriormente, a aliança entre o movimento sindical e as ONGs orientou-se para preparar a participação conjunta dos dois setores em Seattle. Estiveram na Conferência representantes da CUT, da CGT, da Força Sindical e do Grupo Agricultura Familiar no Mercosul. Na Conferência de Seattle, o movimento sindical apoiou e tomou parte na manifestação organizada pela poderosa central sindical americana American Federation of Labor - Congress of Industrial Organizations (AFL-CIO) a favor da adoção das cláusulas social e ambiental. A manifestação, que reuniu um número expressivo de participantes, representou um momento importante na mobilização do ativismo global em Seattle, resultando na reorientação da posição do governo americano acerca desses temas e, conseqüentemente, ajudando a bloquear as negociações em curso. 
Estruturas Domésticas e Grupos de Interesse:

A Formação da Posição Brasileira...

Com efeito, em resposta às manifestações, o então presidente Bill Clinton, em Seattle, defendeu a criação de um grupo de trabalho na OMC para estabelecer padrões trabalhistas que passassem a fazer parte de todos os acordos, bem como a instituição de sanções comerciais em caso de desrespeito àquelas normas ${ }^{27}$. A mudança de postura do governo americano, que até aquele momento ainda não declarara o apoio explícito às reivindicações da AFL-CIO e do movimento ambientalista americano $^{28}$, esteve relacionada, principalmente, aos seus objetivos eleitorais: conseguir a adesão do eleitorado democrata e o apoio da poderosa central sindical americana à eleição do seu vice-presidente, $\mathrm{Al}$ Gore. $\mathrm{O}$ comportamento do presidente americano resultou na intensificação das clivagens entre os países desenvolvidos e em desenvolvimento e contribuiu para dificultar o estabelecimento de um acordo para o lançamento da nova rodada de negociações multilaterais sobre o comércio ${ }^{29}$.

Dessa maneira, o desempenho das centrais sindicais caracterizou-se por buscar a "socialização do conflito", estendendo politicamente sua abrangência (Schattschneider, 1960:3-7), tendo em vista os limites de atuação junto ao governo - questão que será desenvolvida mais adiante - e a existência de recursos de poder alternativos presentes na constituição de coalizões transnacionais.

A proposta de agenda da CUT para Seattle divergiu significativamente da que foi apresentada pelos empresários e da que foi defendida pelo governo brasileiro.

A CUT posicionou-se contra a prioridade dada à agricultura de exportação na agenda brasileira por duas razões. Em primeiro lugar, porque a produção de alimentos, visando ao mercado interno, deveria ser o foco de políticas do governo. De acordo com a central sindical, a agricultura familiar tinha sido muito prejudicada nos últimos anos: "[...] cerca de 900 mil pequenas propriedades rurais foram eliminadas entre 1985 e 1996" (Boletim CUT Mercosul, 1999, nº 13:4). 
Além disso, o processo de liberalização contribuíra para “[...] o desmantelamento das políticas de crédito com subsídio, a abertura às importações, o fim das políticas de garantia de renda e de proteção do mercado interno" (ibidem). Em segundo lugar, a CUT destacou o risco de a pauta de exportações brasileiras ficar restrita aos produtos de menor valor agregado. Dessa forma, o país passaria a aceitar uma situação de inferioridade no comércio internacional, ditada pelos países desenvolvidos que determinariam o volume do que era exportado, bem como a qualidade dos produtos (Jakobsen, 1999b:25).

A agenda sugerida pela CUT incluía: o acompanhamento das negociações para verificar o quanto a liberalização implicaria a geração de renda e emprego; a defesa de medidas rigorosas contra aqueles países cuja produção agredisse o meio ambiente; e a instituição de um padrão de qualidade na produção, a partir das regras trabalhistas estabelecidas pela OIT. Para impedir o uso protecionista da cláusula social, a CUT propôs o estabelecimento de incentivos positivos para quem respeitasse as normas trabalhistas e que, só em último caso, sanções punitivas fossem aplicadas (ibidem).

As Organizações de Agricultores Familiares do Mercosul e mais Chile e Bolívia lançaram, ainda, a Carta de Florianópolis, no Seminário Agricultura Familiar e Mercosul, promovido pela CUT em outubro de $1999^{30}$, na qual defenderam para a rodada de negociações em Seattle "[...] padrões de comércio coerentes com o desenvolvimento e fortalecimento dos sistemas produtivos baseados na agricultura familiar com a produção de alimentos saudáveis, com a eliminação da fome, garantindo a seguridade alimentar de nossos países" (Boletim CUT Mercosul - Encarte, 1999, nº 14:29). Dessa maneira, a pauta dos trabalhadores diferenciou-se da pauta dos empresários em dois aspectos importantes: a não centralidade da questão agrícola e o apoio às cláusulas social e ambiental. As implicações dessas diferenças para a credibilidade da posição oficial brasileira serão discutidas na Conclusão. 
Estruturas Domésticas e Grupos de Interesse: A Formação da Posição Brasileira...

\section{As Preferências do Governo e o seu Relacionamento com a Sociedade Civil}

A abertura econômica, por um lado, e a liberalização política, por outro, foram fatores que, segundo Lima (2000:295), contribuíram para modificar " $[. .$.$] a natureza da política externa que, além de represen-$ tar interesses coletivos no plano mundial, passou a ter que negociar interesses setoriais, inserindo-se diretamente no conflito distributivo interno". Em vista disso, a formulação da política externa passou a exigir o estabelecimento de canais de comunicação entre o Poder Executivo e a sociedade. O relacionamento permitiria que os negociadores brasileiros conhecessem os possíveis impactos que as propostas em jogo pudessem vir a ter sobre os diferentes setores econômicos e sociais, bem como proporcionaria à sociedade o acesso a informações relevantes das negociações comerciais internacionais.

Ademais, uma relação mais estreita entre a diplomacia e a sociedade tornaria a política externa mais representativa e legítima. O interesse nacional, portanto, não seria formulado de modo insulado, mas poderia representar o resultado de um processo interno de compatibilização de posições conflitantes.

A importância do relacionamento entre o setor privado e a burocracia do Executivo justifica-se pela participação limitada que o Congresso Nacional teve na elaboração da agenda brasileira para Seattle. A participação dessa instituição nas decisões de política externa no caso do Brasil tem se restringido à fase posterior à negociação, quando então o acordo é submetido à aprovação. Nesse momento, os constrangimentos colocados por possíveis sanções de outros países à rejeição de um acordo já negociado limitam a capacidade de atuação do Legislativo (Lima e Santos, 1998).

O Congresso só atuou, portanto, como um fórum de discussão quando das audiências públicas promovidas pela Subcomissão Perma- 
nente da Rodada do Milênio - Negociações dos Acordos de Comércio Internacional, criada, em princípio de 1999, no âmbito da Comissão de Agricultura e Política Rural da Câmara dos Deputados ${ }^{31}$. Em vista disso, o seu poder de influência foi reduzido.

Já no início do governo Fernando Henrique se tornou claro, para a diplomacia, que era necessário construir laços mais amplos e constantes com a sociedade. A visão da maior permeabilidade do Itamaraty aos influxos da sociedade civil foi consubstanciada no conceito de diplomacia pública: a participação dos empresários, dos sindicatos, das ONGs, além do Congresso Nacional, na formulação da política externa (Lampreia, 1995:19). De acordo com o então ministro das Relações Exteriores, Luiz Felipe Lampreia, “O Itamaraty não cria interesses nacionais, ele os identifica e os defende, com um mandato da sociedade, à qual presta contas [...]" (ibidem).

Ainda em 1995, a preparação das posições brasileiras para a Conferência de Copenhague sobre Desenvolvimento Social e para a Conferência sobre os Direitos da Mulher em Pequim, bem como em 1996, para o Habitat II, contou com o envolvimento de centrais sindicais, ONGs, associações profissionais, sociais e representantes do setor produtivo (INESC, 1995:12), indicando que a noção de diplomacia pública detectava uma necessária atualização do comportamento da instituição diplomática.

Porém, no que diz respeito à participação da sociedade civil nas negociações multilaterais de comércio, o aggiornamento da diplomacia procedeu em ritmo mais lento.

O Fórum Empresarial das Américas, criado para proporcionar espaço de avaliação pelos empresários das negociações governamentais, sofreu, durante algum tempo, a interferência do governo na formação da delegação brasileira. Sua composição dependia de convite feito pelo Itamaraty, que não levava necessariamente em conta a representatividade junto ao setor do empresário convidado (Santana, 2000:68-69). 
Estruturas Domésticas e Grupos de Interesse:

A Formação da Posição Brasileira...

A Seção Nacional da ALCA (Senalca), instituída pelo governo em 1996 com o objetivo de reunir os vários setores da burocracia atuantes nos Grupos de Trabalho Hemisféricos da ALCA e interessados especificamente nele, demorou a contar com a participação do setor privado (ibidem).

Cabe ressaltar, ainda, que em agosto de 1998 se tornaram públicas as preocupações de alguns diplomatas e ex-ministros de governo em relação à capacidade brasileira de enfrentar, de forma eficiente, o desafio que representava uma nova rodada multilateral de comércio exterior diante da complexidade da agenda futura de negociações. Entre os vários problemas apontados por eles, destacaram-se: inexistência de uma articulação integrada entre os diversos setores do empresariado; ausência de elos mais estruturados entre o setor privado e a diplomacia responsável pela negociação na OMC; e reduzida interação das diversas esferas, dentro do Executivo, responsáveis por decisões no âmbito do comércio exterior ${ }^{32}$.

Porém, o estabelecimento de um canal de comunicação interburocrático e entre o Executivo e a sociedade civil com vistas à preparação da posição brasileira nas negociações multilaterais de comércio ocorreu apenas em 10 de junho de 1999, com a criação do Grupo Interministerial de Trabalho sobre Comércio Internacional de Mercadorias e de Serviços (GICI).

Como está estabelecido no decreto presidencial que o instituiu, o GICI pretendia ser "o núcleo de formulação e coordenação da posição brasileira a respeito dos trabalhos e das negociações conduzidas na esfera da Organização Mundial do Comércio [...]"33. Sediado no Ministério das Relações Exteriores, ele era presidido pelo subsecretário-geral para Assuntos de Integração, Econômicos e de Comércio Exterior do Ministério das Relações Exteriores.

A participação da burocracia no GICI foi assegurada pelo próprio decreto, que estipulou, como membros natos, um representante de cada 
um dos seguintes Ministérios: da Fazenda; do Desenvolvimento, Indústria e Comércio; da Agricultura, Abastecimento e Pecuária; da Ciência e Tecnologia; do Comércio e Gestão; do Meio Ambiente; bem como um representante da Secretaria-Executiva da Câmara de Comércio Exterior do Conselho de Governo.

O envolvimento da sociedade civil, por sua vez, embora previsto no artigo $4^{\underline{0} 34}$, não foi estabelecido a priori, como ocorrera com os diferentes setores da administração governamental; caberia ao próprio GICI promovê-lo. Dessa maneira, a participação do setor privado dependia de convite oficial. As principais organizações de representação de interesses do setor produtivo e dos trabalhadores, no entanto, foram convidadas a participar das reuniões do GICI.

As reuniões promovidas pelo $\mathrm{GICI}^{35}$ terminaram por apoiar uma proposta oficial ampla de agenda que, claramente, se aproximou das preferências do empresariado, como será examinado mais adiante. Em conseqüência, elas colaboraram na construção de um respaldo interno da posição brasileira encaminhada à OMC.

Porém, de acordo com a CEB e o Fórum, o GICI representou, naquele momento, uma resposta do governo às pressões da sociedade por um maior envolvimento nas negociações, bem como um espaço em que a diplomacia transmitiu informações a respeito do andamento das negociações internacionais. Dessa maneira, para o setor empresarial, o GICI preencheu, antes, uma função simbólica - legitimar uma posição oficial - e informativa, do que um espaço de formulação de decisão.

É importante destacar que o GICI não era o único espaço em que a articulação entre as preferências dos grupos de interesse do empresariado e da burocracia do Executivo estava se processando. Como visto anteriormente, a CEB e o Fórum comunicavam-se também com o MNDIC e com o MAPA, respectivamente. Dessa maneira, o GICI 
Estruturas Domésticas e Grupos de Interesse:

A Formação da Posição Brasileira...

atuou, sobretudo, como um fórum de coordenação de posições entre a burocracia e o setor produtivo.

Além disso, as reuniões do GICI não contribuíram para que a posição oficial brasileira se acercasse das demandas do movimento sindical. Os fatores que explicam essas diferenças serão analisados no final desta seção.

A questão agrícola - acesso a mercados, subsídios à exportação e apoio doméstico - adquiriu, desde a Rodada Uruguai, uma importância estratégica nas negociações multilaterais de comércio brasileiras. Durante a Rodada Uruguai, juntamente com outros membros do Grupo de Cairns, o Brasil trabalhou intensamente para que fosse aprovado um acordo que incluísse a agricultura nas regras do GATT, o que efetivamente ocorreu ${ }^{36}$. Contudo, os resultados do Acordo Agrícola foram bastante limitados. Por conseguinte, os níveis aplicados de subsídios à exportação e de apoio doméstico continuaram elevados, criando distorções no comércio agrícola e trazendo grandes prejuízos para as exportações brasileiras.

Por outro lado, a competitividade do agronegócio gerava, desde 1990 , saldos positivos e crescentes na sua balança comercial ${ }^{37}$. Tendo em vista a dependência do país das divisas estrangeiras, a expansão do desempenho daquele setor se constituía em importante recurso para o crescimento econômico.

Desse modo, a agricultura foi colocada como a questão de maior importância da agenda governamental brasileira. Tratava-se de defender a eliminação dos subsídios à exportação, o fim da escalada tarifária e dos picos tarifários e a redução dos apoios domésticos, que distorciam o comércio, utilizados pelas economias mais desenvolvidas da União Européia, dos Estados Unidos e do Japão.

Outros pontos da agenda defendida pelo governo incluíram: revisão do acordo antidumping, tornando suas regras mais claras e transpa- 
rentes para que as medidas não fossem utilizadas de forma arbitrária ou como instrumento protecionista; revisão do acordo de subsídios e medidas compensatórias de modo a possibilitar aos países em desenvolvimento formular políticas de crescimento econômico; introdução no acordo de investimento (TRIMS) de provisões que possibilitassem também a implementação de políticas de desenvolvimento por parte dos países em desenvolvimento.

A posição do governo brasileiro em relação às cláusulas ambiental e social foi oposta à postura defendida pelas centrais sindicais. A utilização dessas cláusulas como mecanismo protecionista, uma expressão dos problemas que afetavam os setores menos competitivos dos países desenvolvidos, demonstrados, por exemplo, nas demandas da

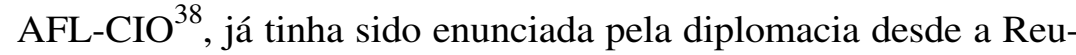
nião de Marraqueche. Por conseguinte, o governo manteve a concepção de que os padrões ambientais e trabalhistas deveriam continuar a ser objeto de exame nos fóruns apropriados, e não na OMC. Como afirmou o ministro das Relações Exteriores, embaixador Luiz Felipe Lampreia, em discurso em Seattle,

“[...] [padrões ambientais e trabalhistas] são dois novos exemplos de temas importados para a agenda internacional do comércio, de uma forma que deixa ampla margem para suspeitas. Não estamos convencidos da necessidade de alterar os acordos da OMC para tratar dessas questões" ${ }^{39}$.

Dessa maneira, cabe ressaltar que a posição brasileira se aproximou das propostas do setor produtivo. Isto também foi reconhecido pela CEB, que destacou que "não houve grandes divergências" entre elas, já que "os conceitos que a coalizão defendia já vinham, de alguma maneira, sendo incorporados pelo governo" ${ }^{\natural 0}$. Dessa forma, a mobilização do setor produtivo contribuiu para respaldar a agenda que o Brasil levou a Seattle.

Porém, foi clara a divergência entre a proposta das centrais sindicais e a pauta oficial brasileira. O núcleo das diferenças concentrou-se em 
Estruturas Domésticas e Grupos de Interesse:

A Formação da Posição Brasileira...

dois aspectos: a centralidade da questão agrícola na agenda oficial do Brasil - rejeitada pelo movimento sindical; e a postura favorável às cláusulas social e ambiental - rejeitada pelo governo.

Neste último caso, vale ressaltar que estavam em jogo visões diferentes a respeito do que significavam aquelas cláusulas: para o movimento sindical, sobretudo a CUT, que entre as centrais sindicais desenvolveu uma proposta mais elaborada da questão, tratava-se de estabelecer mecanismos integrados às relações de comércio que limitassem o uso indiscriminado do meio ambiente e o desrespeito às condições do exercício do trabalho ${ }^{41}$; para o governo brasileiro, tais reivindicações se constituíam em pressões protecionistas dos países desenvolvidos.

Essas duas concepções estavam também presentes no movimento ativista global e abrangente de uma grande coalizão entre protecionistas e "principistas" (Aaronson, 2001), o que dificultou a possibilidade de entendimento entre o movimento sindical e o governo, alocados em lados opostos.

Por fim, é possível também destacar a presença de uma perspectiva desenvolvimentista nas divergências expressas pela CUT a respeito da centralidade da questão agrícola na agenda brasileira. Para a central sindical, tratava-se de o país evoluir por meio da instituição, via atuação do Estado, de uma pauta de exportações com maior valor agregado. Ocorreram, dessa forma, diferenças a respeito de orientações econômicas que, estendidas às negociações comerciais internacionais, resultaram em mais um fator de separação entre a CUT e a diplomacia.

\section{Conclusão}

Este trabalho analisou o processo de formação da agenda brasileira para a Conferência Ministerial de Seattle mediante três pontos de 
vista: o papel do processo de internacionalização da economia a partir do início dos anos 90; o desenvolvimento de organizações de representação de interesses dos empresários e da constituição de alianças transnacionais das organizações representativas de interesses dos trabalhadores; e as relações que se estabeleceram entre o Estado e a sociedade civil.

Nesta conclusão, os principais resultados alcançados são, em um primeiro momento, abordados e discutidos com a utilização do conceito de estruturas domésticas sugerido por Rissen-Kapen (1995). Posteriormente, focalizar-se-ão as implicações dos resultados para a credibilidade e o poder de barganha dos negociadores brasileiros.

O conceito de estruturas domésticas abrange três dimensões: as instituições políticas do Estado, seu relacionamento e o grau em que o poder decisório é mais ou menos concentrado no Poder Executivo; a estrutura de formação das demandas da sociedade e o grau em que elas são mais ou menos centralizadas; e o sistema de intermediação de interesses e o grau em que eles são consensuais ou polarizados ${ }^{42}$.

Em relação à dimensão das instituições políticas, este artigo sugere que a redução da autonomia do Itamaraty foi acompanhada pela ampliação do processo de tomada de decisão à participação de outros atores burocráticos. Por consequiência, ele tornou-se mais fragmentado e competitivo; porém, continuou a se concentrar no Executivo. Nesse contexto, a influência do Congresso Nacional foi nula.

A respeito da segunda dimensão - a estrutura de formação da demanda -, observou-se um processo mais pluralista e concorrente com a criação de organizações supra-setoriais que passaram a articular as preferências do setor produtivo. Além disso, sobressaiu-se a mobilização significativa por parte do movimento sindical a respeito da agenda multilateral e o desempenho destacado da CUT nesse processo. 
Estruturas Domésticas e Grupos de Interesse:

A Formação da Posição Brasileira...

Cabe salientar, ainda, que as divergências entre a proposta do movimento sindical e a posição oficial do país indicam concepções diversas em relação ao seu modelo de desenvolvimento e a respeito da adoção de cláusulas sociais e ambientais na OMC, que dificilmente seriam superadas no contexto de formação da agenda brasileira para Seattle.

Porém, é relevante destacar que a divisão do setor empresarial em relação à adoção da cláusula ambiental e a posição defensiva deste setor a respeito da redução de tarifas industriais e da abertura do setor serviços ressoam nas preocupações do movimento sindical sobre os efeitos de uma agenda liberalizante sobre o emprego e a renda dos trabalhadores.

Em vista disso, este artigo ressalta que uma articulação entre as organizações representativas do empresariado e as centrais sindicais poderia ter contribuído para produzir um entendimento, ainda que parcial, entre os dois setores. Tal fato, possivelmente, colaboraria para aumentar a credibilidade da posição oficial, aproximando as duas agendas - a da sociedade civil e a do governo - e dando um respaldo doméstico mais amplo à proposta brasileira. $\mathrm{O}$ relacionamento entre o contexto institucional e o processo de formação de demandas sociais ocorreu por meio de vínculos pouco estruturados entre as organizações representativas do empresariado e determinados setores da burocracia governamental. Esses vínculos constituíram espaços nos quais se procedeu, ainda que de modo informal, à negociação entre as preferências de setores da burocracia governamental e as do empresariado. O relacionamento ainda aponta para a "politização" do processo decisório, ainda que este tenha sido feito no interior da burocracia do Executivo; isto é, observou-se a constituição de alianças com orientações mais ou menos liberalizantes entre grupos de interesse empresariais e setores burocráticos. 
O sistema de agregação de demandas adquiriu também um feitio bifronte: aproximando-se da dimensão consensual, representada pelos entendimentos entre o setor empresarial e o governo e, polarizada, quando se observa o padrão de comportamento do movimento sindical.

No caso do relacionamento entre o Itamaraty e a sociedade civil, este artigo destaca que a criação do GICI representou um avanço no processo de construção da posição externa do país, na medida em que, por meio desse órgão, se procurou abrir a discussão sobre essa questão para o setor privado. No entanto, o GICI apresentou aspectos pouco estruturados no modo de organizar a participação da sociedade civil, e não foi percebido pelo empresariado como um organismo que respondeu, de modo efetivo, às suas demandas de um vínculo institucionalizado entre o governo e o setor produtivo. Pelo contrário, o setor empresarial enfatizou a dimensão simbólica do GICI.

Dessa maneira, o que se verificou foi que as estruturas domésticas com o domínio da arena executiva - contribuíram para que as preferências empresariais influenciassem a formulação da posição brasileira nas negociações multilaterais de comércio, mas não colaboraram para canalizar as preferências do movimento sindical.

Estudos recentes sobre as negociações multilaterais de comércio no Brasil, inspirados no jogo de dois níveis proposto por Putnam (1993), têm ressaltado a relevância de se considerar o processo de formação da posição do país em relação ao grau de credibilidade e poder de barganha dos representantes no âmbito negociador (Lima e Santos, 1998; Lima, 2000; Santana, 2000; 2001).

A credibilidade diz respeito ao grau em que a construção da postura externa é realizada com a consulta ao Congresso Nacional e aos grupos de interesse domésticos (Lima e Santos, 1998). A credibilidade é relevante, quer do ponto de vista interno, expressando a representatividade da proposta, quer do ponto vista externo, sinalizando para os 
Estruturas Domésticas e Grupos de Interesse:

A Formação da Posição Brasileira...

opositores na mesa de negociações que o que está sendo demandado ou oferecido pelo país tem condições de ser ratificado internamente.

O poder de barganha, por sua vez, é apreciado a partir do estabelecimento, por parte do Legislativo, dos parâmetros do processo negociador (idem), nos moldes da experiência do Congresso dos EUA com os mecanismos de "via rápida". A relevância desses mecanismos decorre do fato de que ele indica para os representantes de outros países os espaços possíveis de negociação.

Levando-se tais questões em consideração, constatou-se que a posição brasileira teve o respaldo apenas do setor empresarial e não logrou alcançar o apoio do movimento sindical. Diferentemente do que ocorreu durante a Reunião da ALCA, em 1997, quando a oposição do movimento sindical contribuiu para o reforço da posição gradualista defendida pelo Brasil (Santana, 2001), na Conferência em Seattle a não inclusão do movimento sindical colaborou para o fortalecimento da coalizão protecionista, formada pelos países desenvolvidos, contrária aos interesses brasileiros.

Além disso, este trabalho ressalta a ausência de envolvimento do Congresso e, conseqüentemente, o limitado poder de barganha do Brasil. Além disso, vale acrescentar que a manutenção do processo de formulação da agenda dentro do Executivo não limita a sua "politização". As divergências que se expressam no interior do Estado poderiam ser mais eficazes e democraticamente tratadas se fossem abordadas no âmbito do Legislativo.

Por fim, um mecanismo de "via rápida" seria mais inclusivo da participação da sociedade, na medida em que possibilitaria incorporar na discussão das negociações multilaterais de comércio todos os grupos que por elas poderiam ser afetados. 


\section{Notas}

1. A diferenciação entre comportamentos de deserção voluntária e involuntária encontra-se em Putnam (1993:440).

2. Rissen-Kapen (1995) utilizou a sua abordagem conceitual para explicar a influência de atores transnacionais nas políticas internas dos Estados. Neste artigo, estou usando o conceito de estruturas domésticas de forma descritiva e heurística, para analisar a influência das preferências dos grupos de interesse do setor privado (empresários e trabalhadores) na formulação da posição brasileira junto à OMC. Além disso, o autor trabalha com uma formulação geral do conceito, enquanto eu o emprego de modo restrito, aplicando-o às estruturas domésticas de uma específica "issue-area": a política externa.

3. De acordo com o embaixador Rubens Ricupero, durante os quatro anos em que ele esteve à frente da delegação brasileira junto à Rodada Uruguai, somente duas missões empresariais brasileiras - uma do setor têxtil e a outra do setor frango - foram a Genebra defender seus interesses (ver "Brasil É Frágil na Negociação com a OMC”, Gazeta Mercantil, 10/8/1998).

4. Ver www.cni.org.br, visitada em 14/2/2003.

5. Entrevista com Sandra Polônia Rios, coordenadora de Integração Internacional da CNI, concedida à autora em 7/5/2003.

6. Idem.

7. Para uma análise detalhada das modificações que aconteceram na agricultura a partir de meados dos anos 80, ver Dias e Amaral (1999).

8. Documento de criação do Fórum Permanente de Negociações Agrícolas Internacionais, Brasília, CNA, 24/2/1999.

9. Idem.

10. Entrevista com Antônio Beraldo Donizeti, chefe do Departamento de Comércio Exterior da CNA, 28/4/2003.

11. Idem.

12. Entrevista com Sandra Polônia Rios, coordenadora de Integração Internacional da CNI, concedida à autora em 7/5/2003.

13. Idem.

14. Idem. 
Estruturas Domésticas e Grupos de Interesse: A Formação da Posição Brasileira...

15. "No terreno das negociações comerciais quão mais imensa e estável for a troca de informações entre o governo e o setor privado, maiores serão as chances de êxito" (Fórum, 1999:11-12). Ver, também, CNI (1999).

16. Gazeta Mercantil, "Exportadores e Governo Discutem Rodada do Milênio", 7/7/1999.

17. Entrevista com Sandra Polônia Rios, coordenadora de Integração Internacional da CNI, concedida à autora em 7/5/2003.

18. Sobre a constituição de alianças entre setores do empresariado e setores da burocracia, consultar Klein (1987).

19. A taxa de desemprego aumentou de modo constante a partir de 1995 , elevando-se de 6,1\% para 8,2\% em 1998, decrescendo para 7\% em 1999 (ver www.ibge.gov.br/brasilãemãsintese/default.htm, visitada em 30/7/2003).

20. Em 1999, a CUT, a CGT e a FS eram membros da CIOSL, bem como da ORIT, filiada à CIOSL (ver www.icftu.org, visitada em 29/7/2003, e www.cioslorit.org, visitada em 29/7/2003).

21. Aquelas normas tratavam de: Proibição de Trabalho Infantil (Convenção 138); Proibição do Trabalho Forçoso (Convenções 29 e 105); Liberdade de Organização Sindical (Convenções 87 e 98); Direito à Negociação Coletiva (Convenções 29 e 105); e Proibição de Discriminação em Relação ao Trabalho (Convenções 100 e 111). Ver Jakobsen (1999a:69).

22. Entrevista com Kjeld Jakobsen, secretário de Relações Internacionais da Prefeitura de São Paulo e secretário de Relações Internacionais da CUT, de maio de 1994 a janeiro de 2003, realizada em São Paulo, em 15/5/2003.

23. Idem.

24. Sediada na Escola Sul da CUT, a organização tem como objetivo monitorar o desempenho das empresas no que diz respeito ao acatamento das normas da OIT e também às condições ambientais da produção (www.observatoriosocial.org.br, visitada em 29/7/2003).

25. A FASE, criada em 1961, atua no âmbito da defesa dos direitos humanos na sua multidimensionalidade; o IBASE, constituído na década de 80, atua na defesa dos interesses dos setores pobres e excluídos (ver, respectivamente, www.fase.org.br e www.ibase.org.br, visitadas em 10/8/2003).

26. Ver http://www.rebrip.org.br, visitada em 10/8/2003.

27. Ver, "Clinton em Campanha na OMC", O Globo, 2/12/1999 e "Desorganização Contribuiu para o Fracasso", Gazeta Mercantil, 6/12/ 1999. 
Maria Izabel V. de Carvalho

28. Sobre as demandas do movimento sindical americano e sua interseção com os pleitos do movimento ambientalista, ver Destler e Balint (1999:43-44).

29. Quando Clinton telefonou a Charlene Barshefsky para lhe contar o teor de suas declarações, "A negociadora teria balançado a cabeça quase em desespero e sussurrado: 'Presidente, isso afeta nossa posição aqui'" (ver "Desorganização Contribuiu para o Fracasso", Gazeta Mercantil, 6/12/1999; ver, também, "Impasse on Trade Delivers a Stinging Blow to Clinton", New York Times, 5/12/1999, www.query.nytimes.com/search/advanced, visitada em 10/8/2000).

30. Seminário Agricultura Familiar e Mercosul: Realidade, Políticas Comparadas e Desafios da Rodada do Milênio, realizado na Escola Sul-CUT, em Florianópolis, 30 de setembro $-1^{\circ}$ de outubro de 1999 . Resultados do Seminário publicados em Boletim CUT Mercosul - Encarte, novembro de 1999.

31. Ressalte-se que não foram feitos registros taquigráficos dessas audiências, de acordo com entrevista do secretário da Comissão da Agricultura, Moisés Lobo da Cunha, em 15/8/2000.

32. Declarações dos embaixadores Celso Lafer e Rubens Ricupero em "O Brasil É Frágil na Negociação com a OMC”, Gazeta Mercantil, 10/8/1998 e em "A Rodada do Milênio Requer Articulação", Gazeta Mercantil, 11/8/1998; e declarações da ex-ministra da Indústria e Comércio em "A Rodada do Milênio Requer Articulação", Gazeta Mercantil,11/8/1998.

33. Decreto do presidente da República, de 10/6/1999, que cria o Grupo Interministerial de Trabalho sobre Comércio Internacional de Mercadorias e de Serviços, e dá outras providências.

34. "O Grupo Interministerial poderá estabelecer formas e canais de colaboração com entidades da sociedade civil que tenham interesse direto nas questões de que trata a OMC" (idem nota 33).

35. O GICI realizou seis reuniões no segundo semestre de 1999: cinco antes de Seattle e uma pós-Seattle.

36. Sobre o papel do Brasil na Rodada Uruguai e os resultados de sua atuação, ver Abreu (1997) e Mello (1996).

37. O saldo da balança comercial do agronegócio aumentou de US\$9,9 milhões em 1990 para US\$ 15,1 milhões em 1997 e manteve-se relativamente constante nos anos de 1998 e 1999 (ver Balança Comercial do Agronegócio, Histórico Evolutivo - US\$ Milhões - Período de 1990 a 2002, www.agricultura.gov.br/spc/balança/evoluçãoãhistoricaãbalançaãanual.pdf, visitada em 24/7/2003). 
Estruturas Domésticas e Grupos de Interesse: A Formação da Posição Brasileira...

38. Segundo a AFL-CIO três eram os problemas que a liberalização comercial tinha trazido para os trabalhadores americanos: diminuíram os postos de trabalho, aumentaram as diferenças entre trabalhadores especializados e nãoespecializados e estimularam condições de trabalho precárias ao proporcionarem aos produtores estrangeiros melhores condições de competitividade vis-à-vis os americanos (Destler e Balint, 1999:43-44).

39. Ver discurso do embaixador Luiz Felipe Lampreia, ministro das Relações Exteriores do Brasil, durante a III Sessão da Conferência Ministerial da OMC, Seattle, 30/11/1999, MRE (Lampreia, 1999).

40. Entrevista com Sandra Polônia Rios, coordenadora de Integração Internacional da CNI, concedida à autora em 7/5/2003.

41. Este último ponto aproximava o discurso da CUT ao das ONGs ambientalistas. Segundo essas organizações, a intensa concorrência do mundo global incentivava os governos e as empresas a reduzirem padrões, quer no que diz respeito ao meio ambiente quer no exercício do trabalho, com o objetivo de atrair investimentos e alcançar melhores condições de competitividade (Destler e Balint, 1999:43-44).

42. A dimensões consensual e polarizada referem-se à presença de uma cultura política que enfatize um processo decisório orientado pelo compromisso e pelo conflito, respectivamente.

\section{Referências Bibliográficas}

AARONSON, Susan A. (2001), Taking Trade to the Streets: The Lost History of Public Efforts to Shape Globalization. Ann Arbor, University of Michigan Press.

ABREU, Marcelo de P. (1997), “O Brasil na Rodada Uruguai do GATT, 1982-1993”, in G. Fonseca Júnior e S. H. Nabuco de Castro (orgs.), Temas de Política Externa Brasileira II (2 $2^{\text {a }}$ ed.). São Paulo, Editora Paz e Terra, pp. 325-351.

BAUMANN, Renato. (1999), “O Brasil nos Anos 1990: Uma Economia em Transição”, in R. Baumann (org.), Brasil: Uma Década em Transição. Rio de Janeiro, Editora Campus, pp. 11-52. 
CNI - Confederação Nacional da Indústria. (1999), “Os Empresários Brasileiros e a Rodada do Milênio: Contribuições da Coalizão Empresarial Brasileira”. Documento $n^{\circ} 1$.

DESTLER, I. M. e BALINT, Peter J. (1999), The New Politics of American Trade: Trade, Labor and the Environment. Washington, D.C., Institute for International Economics.

DIAS, Guilherme L. da S. e AMARAL, Cicely M. (1999), "Mudanças Estruturais na Agricultura Brasileira, 1980-1998”, in R. Baumann (org.), Brasil: Uma Década em Transição. Rio de Janeiro, Editora Campus, pp. 223-253.

DINIZ, Eli e BOSCHI, Renato. (2000), “Associativismo e Trajetória Política do Empresariado Brasileiro na Expansão e Declínio do Estado Desenvolvimentista”. Teoria e Sociedade, nº 5, pp. 48-81.

FÓRUM - Fórum Permanente de Negociações Agrícolas Internacionais. (1999), "Perspectivas da Próxima Rodada de Negociações Agrícolas na OMC". Preços Agrícolas, nº 156, outubro, pp. 11-15.

GOLDSTEIN, Judith e MARTIN, Lisa. (2000), "Legalization, Trade Liberalization, and Domestic Politics: A Cautionary Note". International Organization, vol. 54, nํㅜ 3, pp. 603-632.

IKENBERRY, G. John. (1988), “Conclusion: An Institutional Approach to American Foreign Economic Policy”. International Organization, vol. 42, nº 1 .

INESC - Instituto de Estudos Sócio-Econômicos. (1995), Informativo Especial, ano VIII, $\mathrm{n}^{\circ} 56$, maio.

JAKOBSEN, K. (1999a), “O que Esperar da Rodada do Milênio?”. CUT/Escola Sul, O Desenvolvimento do Comércio Mundial: As Instituições, o Papel das Multinacionais, o Impacto na Agricultura e Rodada do Milênio, pp. 65-71.

(1999b), Palestra proferida no Painel Tendências da Integração Regional e Agenda da Rodada do Milênio da Organização Mundial do Comércio. Seminário Agricultura Familiar e Mercosul: Realidade, Políticas Comparadas e Desafios da Rodada do Milênio. Boletim CUT Mercosul - Encarte, Florianópolis, SC, novembro, pp. 23-26.

KATZENSTEIN, Peter J. (1976), “International Relations and Domestic Structures: Foreign Economic Policies of Advanced Industrial States". International Organization, vol. 1, nº 30, pp. 1-45. 
Estruturas Domésticas e Grupos de Interesse: A Formação da Posição Brasileira...

KEOHANE, Robert O. e MILNER, Helen V. (1996), Internationalization and Domestic Politics. Cambridge, Cambridge University Press.

KLEIN, Lúcia. (1987), "Bens de Capital e Estado no Brasil: A Implementação do Programa de Eletricidade". Revista Brasileira de Ciências Sociais, vol. 1, nº 3, pp. 83-101.

LAFER, Celso. (1999), Comércio, Desarmamento, Direitos Humanos: Reflexões sobre uma Experiência Diplomática. São Paulo, Editora Paz e Terra.

LAMPREIA, Luiz Felipe. (1995), “A Política Externa Brasileira no Governo Fernando Henrique Cardoso”. Papers, n 20, Konrad-Adenauer-Stiftung, pp. $17-42$.

(1999), Discurso durante a III Sessão da Conferência Ministerial da OMC. Seattle, 30 de novembro.

LIMA, Maria Regina Soares de. (2000), “Instituições Democráticas e Política Exterior”. Contexto Internacional, vol. 22, nํㅡㄹ, pp. 265-303.

e SANTOS, Fabiano. (1998), O Congresso Brasileiro e a Política de Comércio Exterior. Trabalho apresentado no XXI Encontro da Latin-American Studies Association (LASA), Chicago, 24-26 de setembro.

MELLO, Flavia de Campos. (1996), “A Nova Agenda do Comércio Multilateral”. Contexto Internacional, vol.18, nํㅡㄹ 2, pp. 239-254.

MILNER, Helen. (1997), Interests, Institutions, and Information: Domestic Politics and International Relations. Princeton, Princeton University Press.

PUTNAM, Robert D. (1993) [1988], "Diplomacy and Domestic Politics: The Logic of Two-level Games", in P. B. Evans, H. K. Jacobson e R. D. Putnam (eds.), Double-edged Diplomacy: International Bargaining and Domestic Politics. Berkeley, University of California Press, pp. 431-468.

RIOS, Sandra P. (1999), “Os Empresários e a OMC”. Carta Internacional, ano VII, $\mathrm{n}^{\mathrm{o}} 76$.

RISSEN-KAPEN, Thomas. (1995), "Bringing Transnational Relations Back In: Introduction", in T. Rissen-Kapen (ed.), Bringing Transnational Relations Back In: Non-state Actors, Domestic Structures and International Institutions. Cambridge, Cambridge University Press, pp. 3-33. 
SANTANA, Helton R. P. (2000), Área de Livre Comércio das Américas (ALCA): Determinantes Domésticos e Política Externa Brasileira. Dissertação de Mestrado, IRI/PUC-Rio.

(2001), "Grupos de Interesse e a Política Externa Brasileira para a ALCA”. Contexto Internacional, vol. 23, nº 1, pp. 167-196.

SCHATTSCHNEIDER, E. E. (1960), The Semi-sovereign People. New York, Holt, Rinehart \& Winston.

THORSTENSEN, Vera. (1999), OMC - Organização Mundial do Comércio: As Regras do Comércio Internacional e a Rodada do Milênio. São Paulo, Aduaneiras.

WEIR, Margaret e SKOCPOL, Theda. (1985), "State Structures and the Possibilities for 'Keynesian' Responses to the Great Depression in Sweden, Britain, and the United States", in P. B. Evans et alii, Bringing the State Back In. Cambridge, Cambridge University Press.

\section{Resumo}

\section{Estruturas Domésticas e Grupos de Interesse: A Formação da Posição Brasileira para Seattle}

O artigo examina o papel dos grupos de interesse dos empresários e dos trabalhadores na formação da posição oficial brasileira para a III Conferência Ministerial da OMC, em Seattle, em 1999. Argumenta-se que esse desempenho deve ser explicado considerando-se a influência de dois fatores: $a$ internacionalização da economia a partir da década de 90 - que tornou a sociedade mais permeável ao ambiente externo - e as estruturas domésticas - que filtraram as preferências das organizações representativas do setor privado. Por um lado, a liberalização econômica e o desenvolvimento de um sistema de regulação internacional do comércio mais interventor desencadearam a mobilização dos grupos de interesse; por outro, a formulação do posicionamento do país esteve concentrada no Executivo, onde vínculos entre o setor empresarial e a burocracia governamental constituíram-se, contribuindo para a convergência de suas preferências. As centrais sindicais, por sua vez, agiram via alianças transnacionais, e suas preferências - divergentes das do empresariado e do governo - não estiveram presentes na posição negocia- 
Estruturas Domésticas e Grupos de Interesse: A Formação da Posição Brasileira...

dora do país. Estes resultados indicam que as estruturas domésticas para as negociações multilaterais de comércio na OMC não foram inclusivas. $\mathrm{O}$ artigo conclui ressaltando que a participação maior do Congresso nesse processo, por meio de mecanismos ex-ante, poderá contribuir para aumentar a representatividade da posição brasileira bem como a sua credibilidade externa.

Palavras-chave: Negociações Multilaterais de Comércio - Estruturas Domésticas - Grupos de Interesse - Organização Mundial do Comércio

\section{Abstract}

\section{Domestic Structures and Interest Groups: The Building up of the Brazilian Position to Seattle}

The article shows the role that business interest group and worker unions had in building up the Brazilian position for the Third Ministerial Summit of WTO, in Seattle, 1999. It argues that that role should be explained by considering two factors: the internationalization of Brazilian economy since the 90's - making the society more sensitive to the events developing in the external environment - and the domestic political structures filtering the preferences of the representative organizations of the private sector. On one hand, the economic liberalization and the development of a more interventionist system of international trade regulation prompted the mobilization of the interest groups; on the other hand, the formulation of Brazilian position was concentrated in the Executive branch where ties between the business sector and the governmental bureaucracy were set up helping for the convergence of their preferences. The worker unions acted through transnational coalitions and their preferences were not included in the country negotiation position. These findings point out that the domestic structures for multilateral trade negotiations were not inclusive. The article ends up stressing that the participation of Congress in trade negotiations by ex-ante mechanisms could make the Brazilian position more representative as well as its external credibility.

Key words: Multilateral Trade Negotiations - Domestic Structures Interest Groups - World Trade Organization 